\title{
Synthesis and Characterization of Phenol/Urea/Formaldehyde and Clay Composites
}

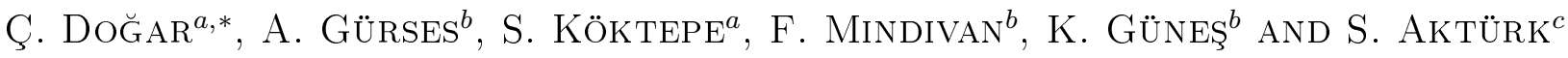 \\ ${ }^{a}$ Faculty of Education, Department of Science Education, Erzincan University, 24030, Erzincan, Turkey \\ ${ }^{b}$ Faculty of Kazım Karabekir Education, Department of Chemistry, Atatürk University, 25240, Erzurum, Turkey \\ ${ }^{c}$ Faculty of Sciences, Department of Chemistry, Muğla University, 48000, Muğla, Turkey
}

\begin{abstract}
Recently, so-called "phenol-formaldehyde-urea resins", which are generally made only by mechanical blending of UF resin and alkaline type PF resins, have been used as adhesives for the manufacturing of wood products. Faster curing PF resins can be also prepared by the addition of urea during or after the resin synthesis to yield co-condensed phenol-urea-formaldehyde (PUF) resins. In this study, resin/clay composites were prepared by in situ polymerization of phenol(18.2\%)-urea(36.3\%)-formaldehyde(45.5\%) (PUF) with the various ratios of organoclay (7.69-45.45\%) and colored organoclay $(3.22-20.0 \%)$. The objective of our work is the investigation of the effect of addition of both organoclay and colored organoclay at different ratios on the textural characteristics. The composites are characterized by X-ray diffraction, Fourier transform infrared spectroscopy techniques and using high resolution transmission electron microscopy images of the samples. It was found that clay layers exfoliated in the resin matrix.
\end{abstract}

DOI: 10.12693 /APhysPolA.125.374

PACS: 81.05.Qk, 82.35.Gh, 82.35.Lr

\section{Introduction}

Among thermosetting polymers, phenol-formaldehyde $(\mathrm{PF})$ resins, as the first fully synthetic polymers formed from phenol reacting with formaldehyde, have been extensively used in many areas [1]. Phenol and ureaformaldehyde resins have dominated such areas as the wood adhesives and molding plastic for many years. Phenolic resins (PF) have demonstrated proven performance in producing exterior quality compositions while low-cost urea-formaldehyde resins (UF) have performed well in interior application. Recently, so-called "phenolformaldehyde-urea resins", which are generally made only by mechanical blending of UF resin and alkaline type $\mathrm{PF}$ resins, have been used as adhesives for the manufacturing of wood products [2].

In the past decade years, many attempts have been made to accelerate the PF resins cure, including using various catalysts and additives such as amide, amines, carbonate, metallic ion, etc. Faster curing PF resins can be also prepared by the addition of urea during or after the resin synthesis to yield co-condensed phenol-ureaformaldehyde (PUF) resins [3]. Considerable attention has been given to PUF co-condensed resins to improve the curing behavior, decrease formaldehyde odor, and reduce the resin cost significantly [4]. Therefore, it is important to understand in more detail the reactions involved, the structures and compositions of the resins and their relation to experimental conditions [1]. Organoclay produced by surface modifications of clay minerals with

*corresponding author; e-mail: cdogar@erzincan.edu.tr cationic surface active agents has received attention because it allows the creation of new materials nanocomposites and new applications [5]. The objective of this work is to characterize and synthesize the virgin PUF polymer and both the PUF/organoclay and PUF/colored organoclay composites.

\section{Experimental}

\subsection{Materials}

Solid urea, phenol, and aqueous solution of formaldehyde $(37 \%), \mathrm{NaOH}$, and $\mathrm{HCl}$ which were used in the synthesis of PUF composites, were supplied from Merck. Also, commercial organo clay was purchased from Sigma Aldrich (Cat. No: 682624). Cetyltrimethylammonium bromide (CTAB) as a cationic surfactant and Remazol Red $\mathrm{RB}$ as a dye stuff which is a commercial reactive textile dye [7] were used without further purification (see Fig. 1). The chemical and mineralogical compositions for the raw clay which has been used to prepare the colored organo clay are given in Table I and also it's the some physical properties in Table II.

XRD diffractograms for the raw clay, the synthesized organoclay and CTAB (cetyltrimethylammonium bromide) (Fig. 1a), and the commercial organoclays (Fig. 1b) are given together with the hypothesized formula of dye in Fig. 1.

As seen from this figure, a wide smectite peak for raw clay at $6-8^{\circ}$ has shifted to left. This depicts that intercalation of $\mathrm{CTA}^{+}$ions from solution into the interlayer region of the clay has occurred and the $\mathrm{CTA}^{+}$ions adsorbed to the surface of clay platelets lead to a significant increase in the basal distance. 


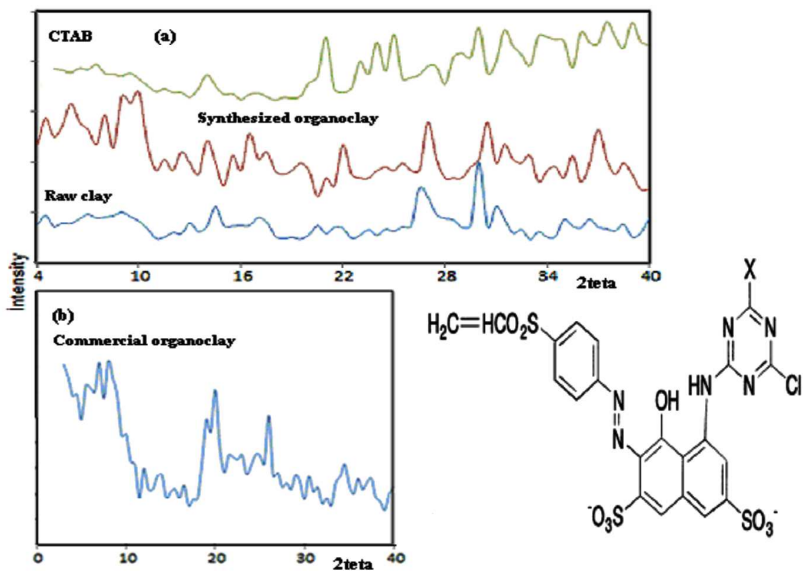

Fig. 1. XRD diffractograms for the raw clay, the synthesized organoclay and CTAB (a), the commercial organoclays (b), and the hypothesized formula of Remazol Red RB.

TABLE I

Some physical properties for the raw clay.

\begin{tabular}{l|c}
\hline \hline clay content [\%] & 76.00 \\
cation-exchange capacity [meq/100 g] & 48.90 \\
specific gravity $\left[\mathrm{g} / \mathrm{cm}^{3}\right.$ ] & 2.61 \\
organic matter content [\%] & 5.10 \\
liquid limit, wL [\%] & 102.00 \\
plastic limit, wP [\%] & 35.00 \\
plasticity index, Ip $(\mathrm{wL}-\mathrm{wP})$ & 67.00 \\
BET $(\mathrm{N} 2)$ surface area $\left[\mathrm{m}^{2} / \mathrm{g}\right]$ & 64.20 \\
\hline
\end{tabular}

${ }^{*}$ Cation exchange capacity (CEC) was determined by the ammonium acetate method [6].

\subsection{Preparation of OPUF and COPUF composites}

In this study, resin/clay composites were prepared by in situ polymerization of phenol(18.2\%)-urea(36.3\%)formaldehyde(45.5\%) (phenol-urea-formaldehyde, PUF) and using the various ratios of organoclay $(7.69-45.45 \%)$ and colored organoclay $(3.22-20.0 \%)$. In order to prepare the colored organoclay, 10 g of raw clay was added to $5 \mathrm{~L}$

TABLE II

Chemical and mineralogical compositions.

\begin{tabular}{c|c|c|c}
\hline \hline Components & {$[\%]$} & Mineral & {$[\%]$} \\
\hline $\mathrm{SiO}_{2}$ & 56.77 & smectite & 25.84 \\
$\mathrm{Al}_{2} \mathrm{O}_{3}$ & 15.66 & chloride & 19.76 \\
$\mathrm{MgO}$ & 8.79 & illite & 16.72 \\
$\mathrm{CaO}$ & 8.44 & kaolinite & 13.68 \\
$\mathrm{~K}_{2} \mathrm{O}$ & 4.04 & analcime & 11.00 \\
$\mathrm{Na}_{2} \mathrm{O}$ & 4.20 & calcite & 7.00 \\
$\mathrm{SO}_{3}$ & 0.91 & quartz & 3.00 \\
$\mathrm{TiO}_{2}$ & 0.84 & feldspar & 3.00 \\
$\mathrm{P}_{2} \mathrm{O}_{5}$ & 0.37 & &
\end{tabular}

of aqueous solution of CTAB (240 mg/L) plus Remazol Red RB (50 mg/L) (see Fig. 2). The mixture was then filtered, dried and sieved thought a sieve of 200 meshes. The commercial organoclay-phenol-urea-formaldehyde (OPUF) composites and the colored organoclay-phenolurea-formaldehyde (COPUF) composites are coded as OPUF1-11 and COPUF12-16, respectively. The preparation procedure was as follows: phenol was mixed with formaldehyde (as a 37\% formalin solution) and urea in a glass reactor equipped with a mechanical stirrer, a thermometer and a reflux condenser and then commercial organoclay and the synthesized organoclay in a given ratio was added to the mixture at $70^{\circ} \mathrm{C}$. Finally, the resultant mixture was stirred for $1 \mathrm{~h}$ and the viscous mixture following after adding a few drops of concentrated $\mathrm{HCl}$ was pelleted mechanically in 2.0 tones $/ \mathrm{cm}^{2}$. Their compositions are given in Table III.

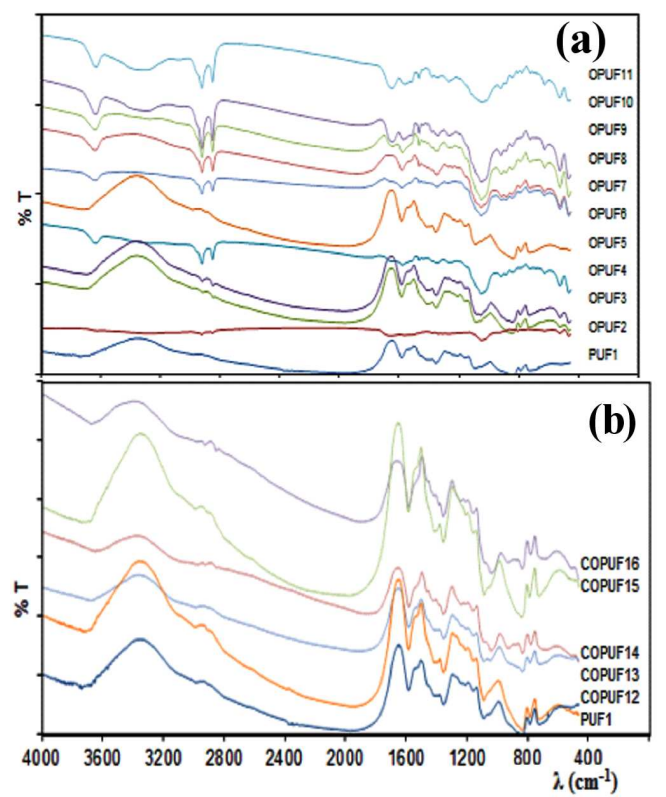

Fig. 2. FTIR spectra for virgin resin, commercial organoclays and the composite in various contents (OPUF) (a) and COPUF composites (b).

The faster reaction of urea than phenol with the phenolic methylol group under alkaline conditions as well as the possibility of reaction with phenol of the methylol groups was formed by the additional attack of $\mathrm{HCHO}$ on urea; the latter reaction drives the reaction of $\mathrm{HCHO}$ on urea, an equilibrium, in favor of methylol ureas and subsequent products [8]. The urea addition can be done in three different manners: at the beginning, at three different middle stages, and at the end of PF resin synthesis (Fig. 1) [9].

1. Addition of urea in the beginning of resin synthesis.

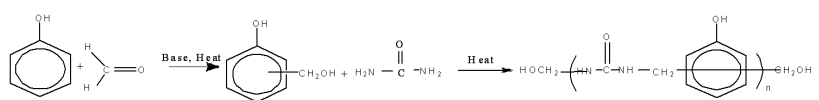


2. Addition of urea at three different middle stages of resin synthesis.

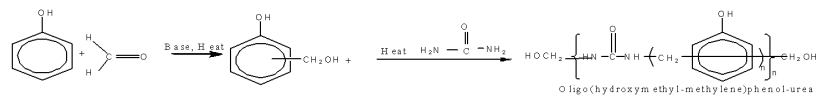

3. Addition of urea at the end of resins synthesis.

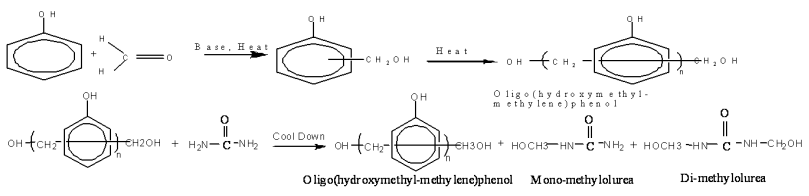

In addition, proposed structure of the alternating copolymer from urea and 2,4,6-triethylolphenol was shown in Ref. [10].

TABLE III

The compositions of PUF composites including commercial organoclay and colored organoclay.

\begin{tabular}{c|c|c|c|c|c}
\hline \hline $\begin{array}{c}\text { PUF } \\
\text { composites }\end{array}$ & $\begin{array}{c}\text { Phenol } \\
\text { [wt\%] }\end{array}$ & $\begin{array}{c}\text { Urea } \\
\text { [wt\%] }\end{array}$ & $\begin{array}{c}\text { Formal- } \\
\text {-dehyde } \\
\text { [wt\%] }\end{array}$ & $\begin{array}{c}\text { Organo- } \\
\text { clay } \\
\text { [wt\%] }\end{array}$ & $\begin{array}{c}\text { Colored } \\
\text { clay } \\
\text { [wt\%] }\end{array}$ \\
\hline PUF1 & 18.2 & 36.3 & 45.5 & - & - \\
OPUF2 & 18.2 & 36.3 & 45.5 & 7.69 & - \\
OPUF3 & 18.2 & 36.3 & 45.5 & 14.3 & - \\
OPUF4 & 18.2 & 36.3 & 45.5 & 20.0 & - \\
OPUF5 & 18.2 & 36.3 & 45.5 & 25.0 & - \\
OPUF6 & 18.2 & 36.3 & 45.5 & 29.4 & - \\
OPUF7 & 18.2 & 36.3 & 45.5 & 33.3 & - \\
OPUF8 & 18.2 & 36.3 & 45.5 & 36.8 & - \\
OPUF9 & 18.2 & 36.3 & 45.5 & 40.0 & - \\
OPUF10 & 18.2 & 36.3 & 45.5 & 42.85 & - \\
OPUF11 & 18.2 & 36.3 & 45.5 & 45.45 & - \\
COPUF12 & 18.2 & 36.3 & 45.5 & - & 3.22 \\
COPUF13 & 18.2 & 36.3 & 45.5 & - & 6.25 \\
COPUF14 & 18.2 & 36.3 & 45.5 & - & 9.10 \\
COPUF15 & 18.2 & 36.3 & 45.5 & - & 14.3 \\
COPUF16 & 18.2 & 36.3 & 45.5 & - & 20.0
\end{tabular}

\subsection{Characterization of OPUF and COPUF composites}

Many techniques, such as XRD, FTIR, and HRTEM have been incorporated to characterize the composites in this study. XRD diffractograms for the composites and filler materials were taken in Bruker D8 Advance X-ray Diffractometer with a $\mathrm{Cu} K_{\alpha_{1}}(1.540 \AA)$ radiation, operating at $40 \mathrm{kV}$ and $30 \mathrm{~mA}$ over a $2 \theta$ range of $1.5-40^{\circ}$. The scanning rate of the instrument was $2 / \mathrm{min}$. FTIR spectra for the commercial organoclay, colored organoclay and prepared composites were taken on a Perkin-Elmer Spectrum-One, by KBr pelleting method from 4000 to $400 \mathrm{~cm}^{-1}$. The all measurements were obtained by an average of 100 scans and a resolution of $1 \mathrm{~cm}^{-1}$. The specimens from the samples were examined by using a JEOL 2100 high resolution transmission electron microscope $\left(\mathrm{LaB}_{6}\right.$ filament) operated at $200 \mathrm{kV}$.

\section{Results and discussions}

\subsection{FTIR analysis}

The analysis results for FTIR spectra for virgin resin, commercial organoclays and the composite in various contents are examined (see Table III). Figure 2 represents FTIR spectra at various ratios of commercial organoclay and colored organoclay. The characteristic absorbances of the phenolic resin and urea-formaldehyde resin are assigned taking account the data in literature [11-15]. The peaks at $880-760 \mathrm{~cm}^{-1}$ are attributed to NH out-of-plane; para-substituted, $\mathrm{CH}$ out of plane; ortho-substituted, respectively. These peaks show out-of-phase stretching vibration of $\mathrm{NH}$ on the clay. The peaks at $1110 \mathrm{~cm}^{-1}$ and $1050 \mathrm{~cm}^{-1}$ are attributed to asymmetric stretching vibration of $\mathrm{C}-\mathrm{O}-\mathrm{C}$ aliphatic ether and the single bond $\mathrm{C}-\mathrm{O}$ stretching vibrations of $-\mathrm{CH}_{2} \mathrm{OH}$ group, respectively. In Fig. 2, the peaks of $\mathrm{C}-\mathrm{O}-\mathrm{C}$ and $\mathrm{C}-\mathrm{O}$ bonds shifted from 1110 to $1120 \mathrm{~cm}^{-1}$ and from 1050 to $1080 \mathrm{~cm}^{-1}$, respectively. The reason of these shifts is ortho-para linkages for $\mathrm{C}-\mathrm{O}$ vibrations. The peak at $1375-1350 \mathrm{~cm}^{-1}$ is associated with bending vibration in plane $\mathrm{CH}$ in $\mathrm{CH}_{2} / \mathrm{CH}_{2} \mathrm{OH} / \mathrm{N}-\mathrm{CH}_{2}-\mathrm{N}$. These vibrations decreased with increase in the amount of organoclay, that is, with energy increased corresponding to this vibration. The peak at $1610-1594 \mathrm{~cm}^{-1}$ corresponding to the $-\mathrm{C}=\mathrm{C}$ - aromatic ring peak shifted to higher energy bands with increase in the amount of organoclay. This indicates that the linkages on phenol rings may occur in three different edges, leading to the formation of more rigid texture. The peak $\left(1680 \mathrm{~cm}^{-1}\right)$ appearing from $\mathrm{C}=\mathrm{O}$ vibration in $-\mathrm{CONH}_{2}$ in the higher ratio of organoclay can be correlated with the presence of a few monomeric urea. The peaks at $2970-2874 \mathrm{~cm}^{-1}$ are associated with in-phase stretching vibration of $-\mathrm{CH}_{2}$-alkane, out-of-phase stretching vibration of $-\mathrm{CH}_{2}$-alkane, respectively. The peak intensities of all composites, except for OPUF6, increase with increased organoclays content. This situation can be explained to the better dispersion of clay particles in the matrix or steric interference to such interactions resulting from the increase in the amount of the clay.

Figure 2b shows FTIR spectra for the composites containing the various ratios of colored organoclay. The peaks at $1270-1260 \mathrm{~cm}^{-1}$ are associated with asymmetric stretch of phenolic $\mathrm{C}-\mathrm{C}-\mathrm{OH}$. These peaks partially shifted to the right with increase in the amount of organoclay. The peaks at $1370-1360 \mathrm{~cm}^{-1}$ that are associated with $\mathrm{S}=\mathrm{O}$ vibrations sharply appear at both the low and high ratios of colored organoclay in cases of COPUF12 and 15 . The peak at $1596-1556 \mathrm{~cm}^{-1}$ also corresponds to the $-\mathrm{C}=\mathrm{C}-$ aromatic ring of phenolic groups. The intensity of these peaks decreases with the increased amount of colored organoclay. The peaks at $1545-1520 \mathrm{~cm}^{-1}$ that are attributed to bending vibration in plane $\mathrm{NH}$ in $\mathrm{NH}-\mathrm{CO}$ shifted to the right and their intensity partially decreased with the increased amount of colored organoclay. Also, the peak at $1486-1470 \mathrm{~cm}^{-1}$ can be attributed to $\mathrm{N}-\mathrm{C}=\mathrm{N}$ vibration of the dye stuff. It was 
observed that the higher ratio of the colored organoclay does not significantly affect the vibrations. The peaks at $1115-1100 \mathrm{~cm}^{-1}$ that are associated with $\mathrm{Si}-\mathrm{O}$ groups were observed at the same intensity in all the composites. Polymer and dye stuff do not affect the groups from clay too much. Interactions carried out between clay with $\mathrm{CTAB}^{+}$ions in the interlayer region. Dye formed semimicelle with $\mathrm{CTAB}^{+}$ions occurred to electrostatically interact with the functional groups and so dye, which is a rather large molecule, was caused by the partial conformational changes during the polymerization. The peak at $810-790 \mathrm{~cm}^{-1}$ corresponding to vibrations of the $\mathrm{C}-\mathrm{Cl}$ does not exhibit any significant shift with the increase in the ratio of colored organoclay. Thus, it can be said that these groups are not affected by the polymerization. The peaks at $860-742 \mathrm{~cm}^{-1}$ are attributed to $\mathrm{CH}$ vibrations out-of-plane, para- and ortho-substituted.

\subsection{XRD and HRTEM analysis}

The structure of the nanocomposites is typically elucidated using XRD and TEM. Although XRD offers a convenient way to determine the interlayer spacing of the silicate layers in the nanocomposite, it is not possible to obtain conclusive results from this technique. XRD and TEM are often combined to ensure the conclusion derived from separate analysis [16]. The microstructure of the PUF composites was studied by HRTEM. In the micrographs in Fig. 3, the dark lines represent the clay layers, and the gray clouds represent the resin matrix [17].

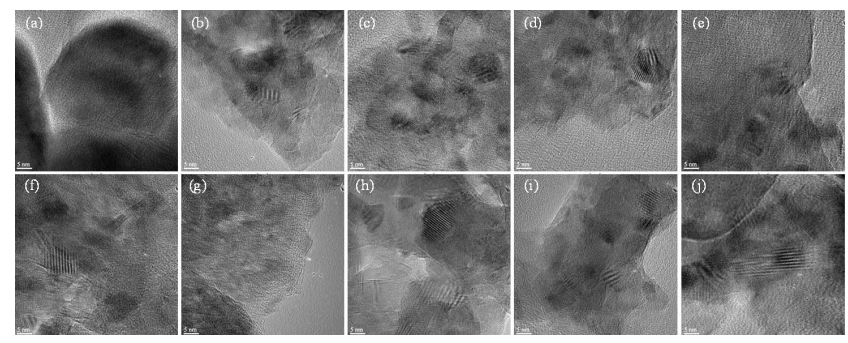

Fig. 3. HRTEM micrographs for OPUF2 (a), OPUF3 (b), OPUF4 (c), OPUF5 (d), OPUF6 (e), OPUF7 (f), OPUF8 (g), OPUF9 (h), OPUF10 (i), and OPUF11 (j).

From Fig. 4 it can be concluded that the presence of organoclay at the low ratio of organoclay affected negatively the crystallization of polymer and the exfoliated layers of the organoclay homogeneously dispersed in the polymeric matrix.
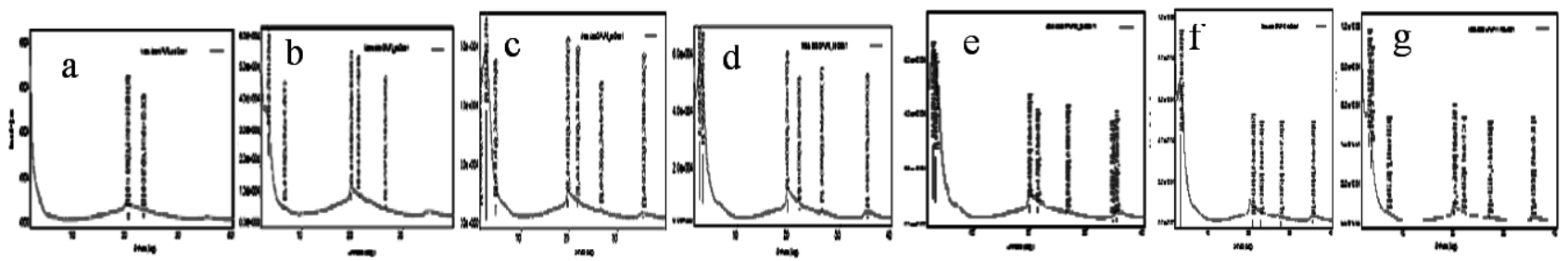

Fig. 4. XRD diffractograms for OPUF3 (a), OPUF4 (b), OPUF5(c), OPUF8 (d), OPUF9 (e), OPUF10 (f), and OPUF11 (g).
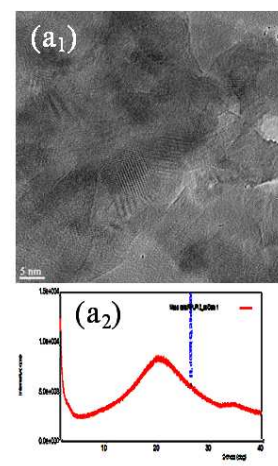
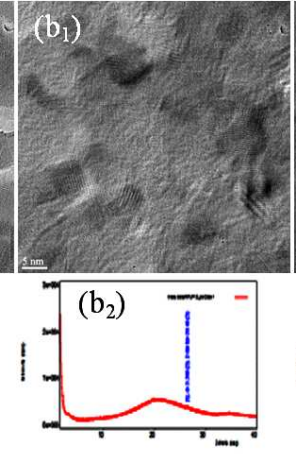
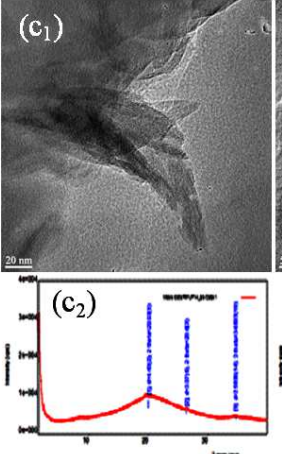
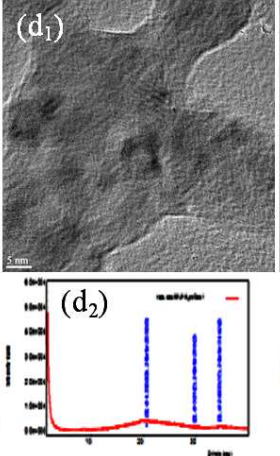

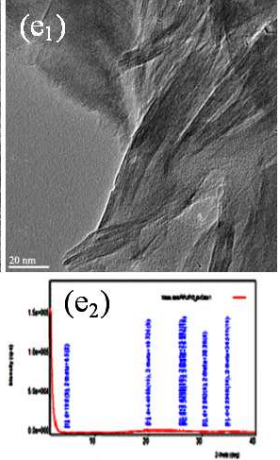

Fig. 5. HRTEM micrographs and XRD diffractograms for COPUF12 $\left(\mathrm{a}_{1} ; \mathrm{a}_{2}\right)$, COPUF13 $\left(\mathrm{b}_{1} ; \mathrm{b}_{2}\right)$, COPUF14 (c $\left.\mathrm{c}_{1} ; \mathrm{c}_{2}\right)$, COPUF15 $\left(\mathrm{d}_{1} ; \mathrm{d}_{2}\right)$, and COPUF16 $\left(\mathrm{e}_{1} ; \mathrm{e}_{2}\right)$, respectively.

From Fig. 5, it can be seen that a typical crystal peak in the composites studied at $20^{\circ}$ appears, probably due to the formation of the cross-linked lattice in the resins as a result of the stimulated effect of organoclay on crystal- lization. In addition, the wide peaks appearing about $4^{\circ}$ at all of the composites, except for OPUF3 and OPUF11, can be attributed to the intercalation of polymer chains to the interlayer region of the clay and the tactoidal 
dispersion of some platelets intercalated of the polymer chains. The characteristic peak shifts to the left with the increased ratio of the organoclay. On the other hand, it should be noticed that a little second peak at the right of the diffractograms appeared with the increased ratio of the organoclay. These peaks may be correlated to the formation of the linear or cross-linked polymeric chains with different sizes. This may also be realized from their HRTEM micrographs.

From Fig. 5 it can be seen that at all of the composites, a broad peak at $2 \theta=20^{\circ}$ appears and its intensity gradationally reduces with the increased ratio of the clay. This peak in the case of COPUF16 completely disappears, showing that the platelets of the clay have exfoliated in the polymeric matrix [13]. According to this, it may be said that the lower amount of organoclay exhibits a stimulant effect in terms of the nucleation of polymer chains, but as the platelets of the clay uniformly dispersed in the polymeric matrix increase, the steric barrier of these exfoliated platelets counter to the nucleation and/or tertiary interactions of the linear polymer chains predominates.

The HRTEM micrographs and XRD diffractograms for these composites clearly show that the anionic dye molecules adsorbed on clay plates directly affect the formation of the polymeric lattice. As can also be seen from their FTIR spectra, the number of $\mathrm{CH}_{2}$ bridges established over the phenol ring at the polymeric chain increased with increasing of the clay content. The fact that the colors of these composites are exactly the same with the color of colored organoclay may reveal that the chromophore groups of dye molecules do not play an active role in the polymerization.

\section{Conclusions}

- In this work, OPUF and COPUF composites were prepared by in situ polymerization method.

- In FTIR analysis, it was seen that the peak intensities of all composites, except for OPUF6 increase with increased organoclays content. This may be explained to the better dispersion of clay particles in the matrix or steric interference to such interactions resulting from the increase in the amount of the clay.

- HRTEM analysis shows that the lower ratio of organoclay affected negatively the crystallization of polymer and the exfoliated layers of the organoclay were homogeneously dispersed in the polymeric matrix.
- The HRTEM and XRD analysis results of the COPUF can be revealed that platelets of the clay have exfoliated in the polymeric matrix and the lower amount of organoclay exhibits a stimulant effect in terms of the nucleation of polymer chains, but as the platelets of the clay uniformly dispersed in the matrix increase, the steric barrier of these exfoliated platelets counter to the nucleation and/or tertiary interactions of the linear polymer chains predominates.

\section{References}

[1] G. He, N. Yan, Polymer 45, 6813 (2004).

[2] B. Tomita, M. Ohyama, C.-Y. Hse, Holzforschung 48, 522 (1994).

[3] D. Fan, J.-Z. Li, J. Chang, Eur. Polym. J. 45, 2849 (2009).

[4] G. He, B. Rield, J. Polym. Sci. Pol. Phys. 41, 1929 (2003).

[5] L.B. Paiva, A.R. Morales, R. Francisco, V. Díaz, Appl. Clay Sci. 42, 8 (2008).

[6] I. Poljansek, U. Sebenik, M. Krajnc, J. Appl. Polym. Sci. 99, 2016 (2006).

[7] Z. Wu, C. Zhou, R. Q1, Polymer Compos. 23, 634 (2002).

[8] A. Pizzi, Handbook of Adhesive Technology, ch: Natural Phenolic Adhesives I: Tannin, 2nd ed., Eds.: A. Pizzi, K.L. Mittal, Dekker, New York 2003, p. 573.

[9] S.M. Lee, Ph.D. Thesis, Mississippi State University, 2003.

[10] H. Lei, G. Du, A. Pizzi, A. Celzard, J. Appl. Polym. Sci. 109, 2442 (2008).

[11] S. Samarzija-Jovanović, V. Jovanović, S. Konstantinović, G. Marković, M. Marinović-Cincovic, J. Therm. Anal. Calorim. 104, 1159 (2011).

[12] B. Tomita, C.-Y. Hse, Int. J. Adhesion Adhesives 18, 69 (1997).

[13] H. Dalir, R.F. Farahani, M. Lévesque, D. Therriault, InTech, New York 2011.

[14] I. Polijansek, M. Krajnc, Acta Chim. Slov. 52, 238 (2005).

[15] A. Gürses, M. Yalçın, C. Doğar, Water Air Soil Poll. 146, 297 (2003).

[16] G. Rivero, A. Vázquez, L. Manfredi, J. Appl. Polym. Sci. 114, 32 (2009).

[17] D. Wang, G. Chang, Y. Chen, Polym. Degr. Stab. 93, 125 (2008). 